\title{
Villitis of Unknown Etiology in the Placenta of a Pregnancy Complicated by COVID-19
}

\author{
Erdener OZER ${ }^{1} \mathbb{D}^{\mathbb{D}}$, Erkan CAGLIYAN² ${ }^{\mathbb{D}}$, Resmiye Irmak YUZUGULDU1 ${ }^{\mathbb{D}}$, Mustafa Cüneyt CEVIZCI ${ }^{1}$ \\ Nuray DUMAN ${ }^{3}$
}

Department of ${ }^{\prime}$ Pathology, ${ }^{2}$ Obstetrics \& Gynecology and ${ }^{3}$ Neonatology, Dokuz Eylul University Hospital, IZMIR, TURKEY

\begin{abstract}
Villitis of unknown etiology (VUE) is noninfectious chronic villitis thought to be associated with fetal growth restriction and stillbirth. COVID-19 and the pandemic SARS-CoV-2 infection can cause an increased risk in pregnant women for potential maternal and fetal complications from an immunological mechanism. We report a 39-week-gestational-age infant delivered to a 37-year-old mother diagnosed with SARS-CoV-2 infection at 37 weeks gestation. The placental examination showed the morphological features of VUE. We showed immunohistochemically that macrophages and CD4-positive T cells predominated in the villous tissue, although elevated numbers of CD8-positive cells were also present. We hypothesize that VUE may represent a maternal anti-viral immune response, in this case to SARS-CoV-2.
\end{abstract}

Keywords: COVID-19, Placenta, SARS-CoV-2, Villitis of unknown etiology

\section{INTRODUCTION}

The emergence of the pandemic severe acute respiratory syndrome coronavirus 2 (SARS-CoV-2) infection and coronavirus disease (COVID-19) has created a serious public health problem. Covid-19 can affect pregnant women because they become an extremely sensitive group during any pandemic of viral infections due to altered immune functions and susceptibility to infection. Although Hosier et al. (1) has demonstrated SARS-CoV-2 to be localized to syncytiotrophoblast cells at the maternal-fetal interface of the placenta, there is no reliable evidence for vertical transmission of the virus in pregnant women with COVID-19; however, an increased prevalence of perinatal problems has been reported $(2,3)$. It is also unexplained yet by which mechanism SARS-CoV-2 virus infection can be effective on the pregnancy outcome because there is little data on adverse pregnancy outcomes in pregnant women with COVID-19 (4).

Placental pathology can provide significant knowledge of SARS-CoV-2 virus infection in pregnancy regarding the wellbeing of both mother and fetus, thus regarding perinatal outcome. In a few recent cohort studies, the placentas of pregnant women infected with SARS-CoV-2 have shown higher rates of maternal or fetal vascular malperfusion features associated with adverse outcomes $(5,6)$. We report herein a case of chronic villitis in the placenta of a

(Turk Patoloji Derg 2021, 37:167-171)

Received : 09.08.2020 Accepted : 01.09.2020 pregnancy complicated by COVID-19. We hypothesize that chronic inflammatory or immune pathological lesions of the placenta may be also effective on the perinatal outcome in SARS-CoV-2 virus infection, and result from an antiviral immune response.

\section{CASE REPORT}

The patient was a 39-week-gestational-age infant delivered to a 37-year-old G2, P1 mother with no significant prior obstetric history. Three days prior to presentation, the mother developed fever, flu-like symptoms, mild sore throat, and a non-productive cough. The molecular detection test by reverse transcription-polymerase chain reaction (RTPCR) for SARS-CoV-2 RNA in a nasopharyngeal swab obtained from the patient on admission was positive. She had no history of social contact with a COVID-19 positive individual. Neither her husband nor her older child had a positive test result for SARS-CoV-2. No further details were available to us.

The mother was admitted for labor and birth. Fetal ultrasound revealed a healthy fetus with an estimated fetal weight within expected range and normal amniotic fluid volume. Laboratory studies revealed normal liver transaminases, as well as normal partial thromboplastin time, fibrinogen, and D-dimer level. Blood smear revealed normal blood count with unremarkable morphology. She
Correspondence: Erdener OZER

Dokuz Eylul University School of Medicine, Department of Pathology,

IZMIR, TURKEY

E-mail: erdener.ozer@deu.edu.tr Phone: : +902324123407 
underwent cesarean section. The boy infant had a birth weight of 3360 grams and a good Apgar score. His RT-PCR test for SARS-CoV-2 was negative. Both mother and infant were discharged in good health.

Macroscopic and microscopic examinations of the placenta were performed according to the standard protocol. The placental disc measured $18 \times 17 \times 2.5 \mathrm{~cm}$ and weighed 564 $\mathrm{g}$ without the fetal membranes or umbilical cord (75th percentile). The umbilical cord showed three vessels and no thrombosis, was $14 \mathrm{~cm}$ in length, was inserted eccentrically, and measured $1.2 \mathrm{~cm}$ in diameter. Placental membranes were translucent, complete, and morphologically normal. The fetal surface showed subchorionic fibrin and both surfaces appeared otherwise normal. On cut section, there was no grossly visible villous lesion.

On histological examination, the villi showed focally an inflammatory infiltrate composed of macrophages and plasma cells as well as many lymphocytes (Figure 1). In addition, mononuclear cells in the decidua and avascular villi adjacent to a subchorionic thrombohematoma were present (Figure 2,3). The maternal vessels did not show any features of decidual vasculopathy. Neither histological chorioamnionitis nor funusitis were seen. The inflammatory infiltrate in the villi and decidua predominantly consisted of macrophages and CD4-positive $\mathrm{T}$ lymphocytes, as demonstrated by immunohistochemistry for CD4, CD8 and CD163 (Figure 4A-D). The pathological diagnosis was made as low-grade chronic villitis graded according to the Amsterdam criteria (7). However, we were not able to demonstrate the presence of SARS-CoV-2 in the placental tissue with histological signs of chronic villitis, and therefore we classified the morphology as villitis of unknown etiology (VUE).

\section{DISCUSSION}

The physiologic and immunologic changes that occur as a normal component of pregnancy can have systemic effects that increase the risk for complications from viral infections. We reported here a case of VUE in the placenta of a successful pregnancy complicated with SARS-CoV-2 infection.

The etiology of chronic villitis is not fully addressed yet. A large proportion of cases of chronic villitis is VUE and may reflect a noninfectious immune response $(8,9)$. However, $41 \%$ of lesions originally classified as VUE have been reported in a study to have a viral infectious etiology demonstrated by electron microscopy (10). We did not plan to demonstrate the presence of SARS-CoV-2 because RTPCR tests for SARS-CoV-2 RNA in the nasopharyngeal swab obtained from the infant were negative.

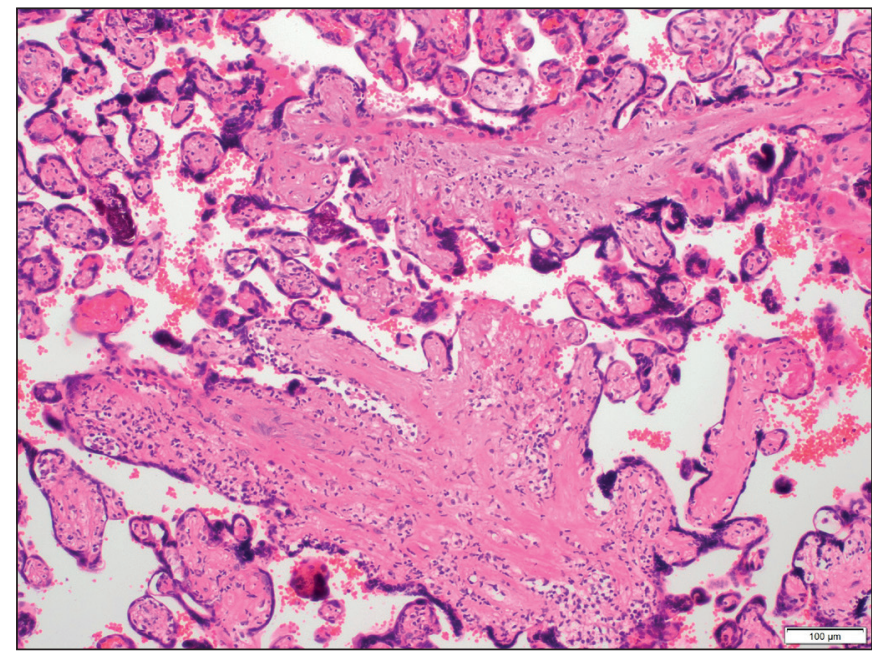

Figure 1: Low-grade chronic villitis characterized by a mononuclear cell infiltrate ( $<10$ inflamed villi per focus) (H\&E; $\mathrm{x} 100)$.

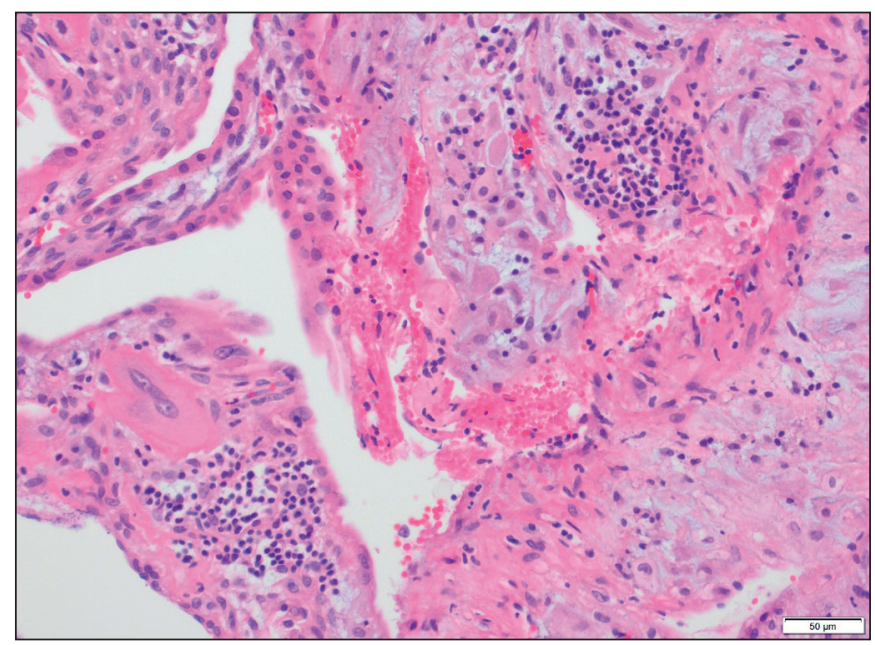

Figure 2: Chronic deciduitis: Predominantly lymphocytic infiltration in the decidua (H\&E; x200).

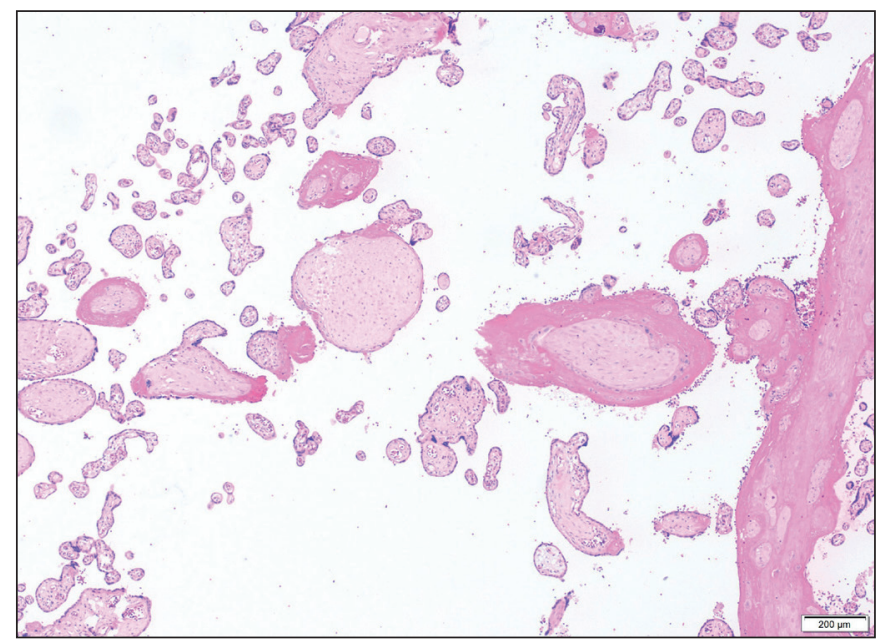

Figure 3: Avascular chorionic villi compatible with fetal vascular malperfusion (H\&E; $\mathrm{x} 40)$. 

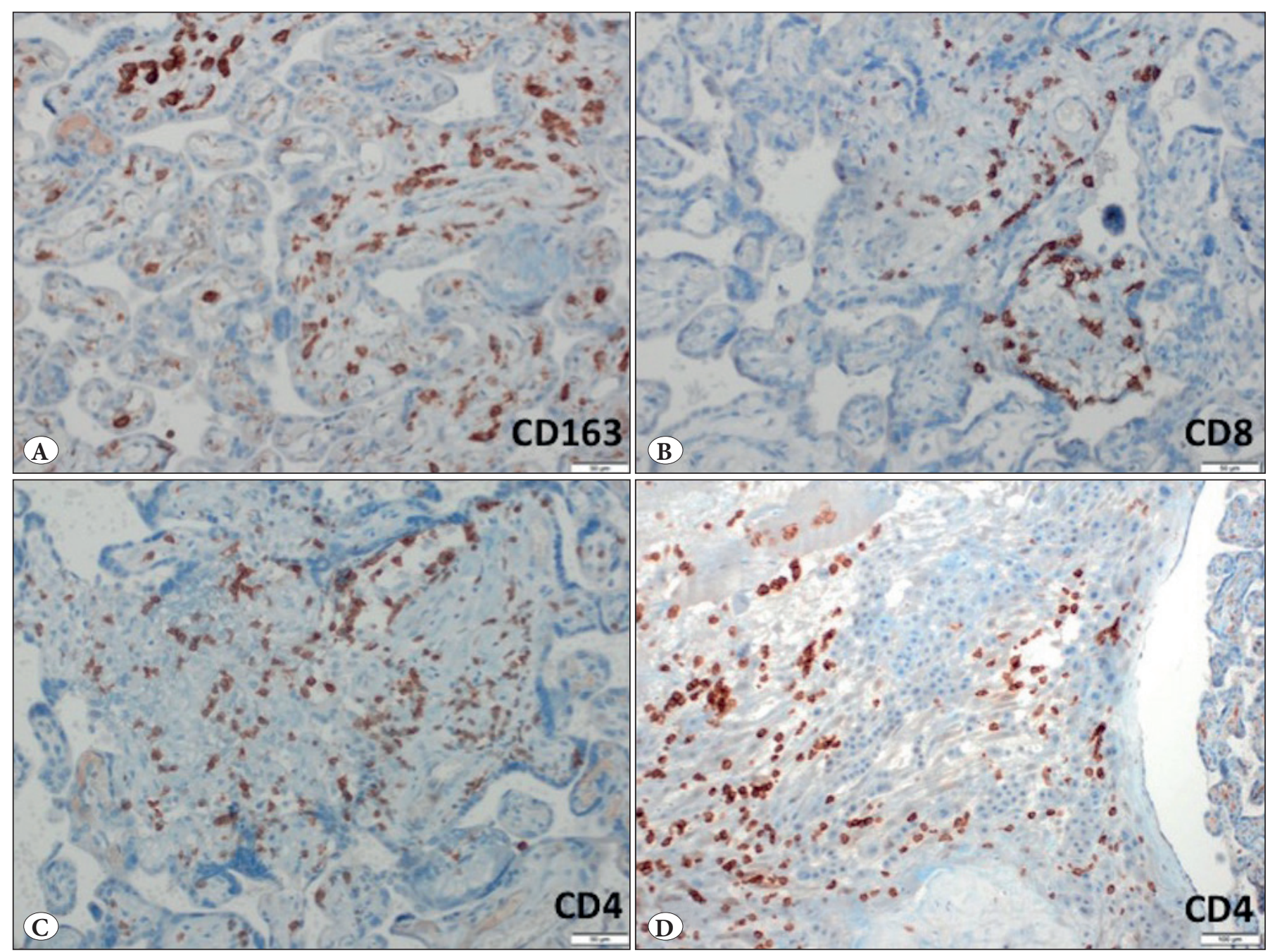

Figure 4: Immunohistochemical findings. A) CD163-positive macrophages in the villi (IHC; x200). B) CD8-positive T lymphocytes in the villi (IHC; x200). C) CD4-positive T lymphocytes in the villi (IHC; x200). D) CD4-positive T lymphocytes in the decidua (IHC; $\mathrm{x} 100)$.

To the best of our knowledge, there is only one case reporting localization of SARS-CoV-2 in the placenta (1). However vertical transmission of the virus is still unproven. We do not know whether the clinical condition of the infected mother may be associated with the risk of viral transmission and the virus might also have been cleared from placental tissue depending on the time between viral infection and labor. We think that the chronic villitis in our case may be unrelated to viral transmission because the mother developed milder symptoms of COVID-19 and the symptoms appeared at the 39th week of pregnancy, only three days prior to presentation.

Recent data regarding VUE in live birth have shown that villous lesions are composed of mainly fetal macrophages and maternal CD4- or CD8-positive T lymphocytes (11).
We showed immunohistochemically that macrophages and CD4-positive $\mathrm{T}$ cells predominated, although elevated numbers of CD8-positive cells were also present. This composition that we observed, with CD4 positive lymphocytes outnumbering CD8 positive lymphocytes, is in accordance with the study of Labarrere et al. (12) and supports the hypothesis that the anti-viral immune response in VUE is of the Th1-type including anti-fetal cellmediated mechanisms.

There is an immunologic paradox in normal pregnancy, which is the shift from Th1- to Th2-type responses. Suppression of anti-fetal cell-mediated responses and a functional predominance of antibody-mediated immunity provide an advantage in the maintenance of a successful pregnancy. The cytokine profile in Th2-type responses 
includes mainly IL-4, IL-10, and TGF- $\beta$, whereas the antiinflammatory cytokines IL-2, IL-6, and IL-12 predominate in Th1-type responses $(13,14)$.

SARS-CoV-2-specific CD4+ T cell and antibody responses in lung lesions were observed in all COVID-19 cases, whereas $\mathrm{CD} 8+\mathrm{T}$ cell responses were observed in not all but most patients in a study (15). In addition, the immunological reaction triggered by SARS-CoV- 2 infection has been shown to be effective in mobilizing numerous cytokines such as IL-1, IL-6, IL-12, IFN- $\gamma$, and TNF- $\alpha$, preferentially targeting lung tissue (16). Therefore, we think that there may be a strong similarity in the characteristics of inflammatory cell distribution and cytokine production among the lung lesions and placental VUE lesions of COVID-19 patients. In accordance with our suggestion, increased levels of IL-2 and IL-12 have been shown in VUE lesions (11). This likely indicates that there may be an inappropriate shift toward the Th2-type immune response in pregnant women with VUE lesions, which may explain the higher risk of stillbirth. Therefore, the presence of VUE may carry a risk of adverse perinatal outcome for COVID-19 infected pregnant patients.

In a recent cohort study, maternal Covid-19 infection was found to be significantly associated with fetal vascular thrombosis (5). Besides, VUE sometimes progresses to obliterative fetal vasculopathy. The presence of cytotoxic CD8-positive $\mathrm{T}$ cells is responsible for the development of the fetal placental vasculopathy often observed in VUE and also the increased apoptosis of intravillous cells $(9,17)$. These may explain why we did not find any features of fetal vascular malperfusion in our case because CD8-positive lymphocytes were relatively low in the lesions. In addition, obliterative fetal vasculopathy occurs in response to chronic inflammation in VUE when there is multifocal involvement (9). This may also explain the absence of fetal vascular malperfusion because chronic villitis in our case was of low grade $(<10$ inflamed villi per focus). Furthermore, there was no gross umbilical cord abnormality or maternal hypercoagulability known to be associated with fetal vascular malperfusion.

We conclude that SARS-CoV-2 infection may be related to VUE resulting from an anti-viral response. As SARS-CoV-2 is a virus, it is likely to induce inflammation. This is a Th1-type response including several types of $\mathrm{T}$ cells, predominantly CD4-positive lymphocytes resulting from a disturbance of normal pregnancy tolerance. The immunogenic activity of these cells is influenced by cytokines that are increased in SARS-CoV-2 infection as well. We therefore hypothesize that the burst of inflammatory cytokines accompanying SARS-CoV-2 infection may produce lesions of VUE. Further studies are needed to prove this hypothesis regarding whether VUE is related to an antiviral immune response in COVID-19.

\section{AUTHORSHIP CONTRIBUTIONS}

Concept: EO, EÇ, ND, Design: EO, Data collection or processing: EO, EÇ, RIY, MCC, ND, Analysis or Interpretation: EO, EÇ, ND, Literature search: EO, Writing: EO, Approval: EO, EÇ, RIY, MCC, ND

\section{REFERENCES}

1. Hosier H, Farhadian SF, Morotti RA, Deshmukh U, Lu-Culligan A, Campbell KH, Yasumoto Y, Vogels CB, Casanovas-Massana A, Vijayakumar P, Geng B, Odio CD, Fournier J, Brito AF, Fauver JR, Liu F, Alpert T, Tal R, Szigeti-Buck K, Perincheri S, Larsen CP, Gariepy AM, Aguilar G, Fardelmann KL, Harigopal M, Taylor HS, Pettker CM, Wyllie AL, Dela Cruz CS, Ring AM, Grubaugh ND, Ko AI, Horvath TL, Iwasaki A, Reddy UM, Lipkind HS. SARSCoV-2 infection of the placenta. J Clin Invest. 2020;130:4947-53.

2. Gujski M, Humeniuk E, Bojar I. Current state of knowledge about SARS-CoV-2 and COVID-19 disease in pregnant women. Med Sci Monit. 2020;9:e924725.

3. Liu H, Wang LL, Zhao SJ, Kwak-Kim J, Mor G, Liao AH. Why are pregnant women susceptible to COVID-19? An immunological viewpoint. J Reprod Immunol. 2020;139:103122.

4. Schwartz DA. An analysis of 38 pregnant women with COVID-19, their newborn infants, and maternal-fetal transmission of SARS-CoV-2: Maternal coronavirus infections and pregnancy outcomes. Arch Pathol Lab Med. 2020 Mar 17. Epub ahead of print.

5. Baergen RN, Heller DS. Placental pathology in Covid-19 positive mothers: Preliminary findings. Pediatr Dev Pathol. 2020;23:17780.

6. Shanes ED, Mithal LB, Otero S, Azad HA, Miller ES, Goldstein JA. Placental pathology in COVID-19. Version 2. Am J Clin Pathol. 2020;154:23-2.

7. Khong TY, Mooney EE, Ariel I, Balmus NC, Boyd TK, Brundler MA, Derricott H, Evans MJ, Faye-Petersen OM, Gillan JE, Heazell AE, Heller DS, Jacques SM, Keating S, Kelehan P, Maes A, McKay EM, Morgan TK, Nikkels PG, Parks WT, Redline RW, Scheimberg I, Schoots MH, Sebire NJ, Timmer A, Turowski G, van der Voorn JP, van Lijnschoten I, Gordijn SJ. Sampling and definitions of placental lesions: Amsterdam placental workshop group consensus statement. Arch Pathol Lab Med. 2016;140:698713.

8. Meijer WJ, Wensing AM, Bruinse HW, Nikkels PG. High rate of chronic villitis in placentas of pregnancies complicated by influenza $\mathrm{A} / \mathrm{H} 1 \mathrm{~N} 1$ infection. Infect Dis Obstet Gynecol. 2014;2014:768380.

9. Redline RW. Villitis of unknown etiology: Noninfectious chronic villitis in the placenta. Hum Pathol. 2007;38:1439-46. 
10. O'Malley A, Gillan JE. The incidence of viral infection causing villitis. Placenta. 2005;26, article 38.

11. Derricott H, Jones RL, Greenwood SL, Batra G, Evans MJ, Heazell AE. Characterizing villitis of unknown etiology and inflammation in stillbirth. Am J Pathol. 2016;186:952-61.

12. Labarrere C, Faulk W, McIntyre J. Villitis in normal term human placentae: Frequency of the lesion determined by monoclonal antibody to HLA-DR antigen. J Reprod Immunol. $1989 ; 16: 127 \mathrm{e} 135$

13. Chaplin DD. Overview of the immune response. J Allergy Clin Immunol. 2010;125(2 Suppl 2):S3-23.

14. Lombardelli L, Aguerre-Girr M, Logiodice F. HLA-G5 induces IL-4 secretion critical for successful pregnancy through differential expression of ILT2 receptor on decidual CD4+ T cells and macrophages. J Immunol. 2013;191:3651-62.
15. Grifoni A, Weiskopf D, Ramirez SI, Mateus J, Dan JM, Moderbacher CR, Rawlings SA, Sutherland A, Premkumar L, Jadi RS, Marrama D, de Silva AM, Frazier A, Carlin AF, Greenbaum JA, Peters B, Krammer F, Smith DM, Crotty S, Sette A. Targets of $\mathrm{T}$ cell responses to SARS-CoV-2 coronavirus in humans with COVID-19 disease and unexposed individuals. Cell. 2020;181:1489-501.

16. Costela-Ruiz VJ, Illescas-Montes R, Puerta-Puerta JM, Ruiz C, Melguizo-Rodríguez L. SARS-CoV-2 infection: The role of cytokines in COVID-19 disease. Cytokine Growth Factor Rev. 2020; (Epub ahead of print)

17. Feeley L, Mooney EE. Villitis of unknown aetiology: correlation of recurrence with clinical outcome. J Obstet Gynaecol. 2010;30:476-9. 